Research Article

\title{
Serum Osteoprotegerin Is a Potential Biomarker of Insulin Resistance in Chinese Postmenopausal Women with Prediabetes and Type 2 Diabetes
}

\author{
Peng Duan, ${ }^{1}$ Min Yang, ${ }^{2}$ Meilin Wei, ${ }^{1}$ Jia Liu, ${ }^{1}$ and Ping Tu ${ }^{1}$ \\ ${ }^{1}$ Department of Endocrinology and Metabolism, Nanchang Key Laboratory of Diabetes, The Third Hospital of Nanchang, \\ No. 2 Xiangshan South Road, Nanchang, Jiangxi 330009, China \\ ${ }^{2}$ Department of Finance, Nanchang Normal University, No. 889 Ruixiang Road, Nanchang, Jiangxi 330009, China
}

Correspondence should be addressed to Ping Tu; tuping8877@126.com

Received 21 August 2016; Revised 28 October 2016; Accepted 14 November 2016; Published 31 January 2017

Academic Editor: Andre Pascal Kengne

Copyright (c) 2017 Peng Duan et al. This is an open access article distributed under the Creative Commons Attribution License, which permits unrestricted use, distribution, and reproduction in any medium, provided the original work is properly cited.

\begin{abstract}
The aim of this study is to investigate the circulating OPG levels in postmenopausal women with diabetes and prediabetes and explore the relationships between serum OPG and insulin resistance. A total of 271 unrelated Chinese postmenopausal women were recruited in this study. The subjects were divided into type 2 diabetes mellitus (T2DM) group ( $n=93$ ), impaired glucose regulation (IGR) $(n=90)$, and normal glucose regulation group (NGR) $(n=88)$, according to different glucose regulation categories. Serum OPG levels were measured by enzyme-linked immunosorbent assay. The serum OPG concentration in NGR group, $151.00 \pm 45.72 \mathrm{pg} / \mathrm{mL}$, was significantly lower than that in IGR group $(169.28 \pm 64.91 \mathrm{pg} / \mathrm{mL})$ $(p=0.031)$ and T2DM group $(183.20 \pm 56.53 \mathrm{pg} / \mathrm{mL}) \quad(p<0.01)$, respectively. In multiple linear regression analysis, HOMA-IR, age, 2hPG, AST, ALP, and eGFR were found to be independent predictors of OPG. Increased serum OPG levels $(\mathrm{OR}=1.009, p=0.006)$ may be a risk factor for insulin resistance. The present study suggests that OPG might be implicated in the pathogenesis of diabetes and is a potential biomarker of insulin resistance in subjects with diabetes and prediabetes.
\end{abstract}

\section{Introduction}

Osteoprotegerin (OPG) is a secreted glycoprotein that belongs to the tumor necrosis factor receptor superfamily. OPG is known to act as a decoy receptor for the receptor activator of nuclear factor $-\kappa \mathrm{B}(\mathrm{NF}-\kappa \mathrm{B})$ ligand (RANKL), which stimulates osteoclastogenesis and bone resorption by binding to its receptor activator of NF- $\kappa$ B (RANK). OPG could prevent RANKL from binding to RANK on osteoclasts, thus, inhibiting osteoclast differentiation and bone resorption [1].

It has been well recognized that OPG could regulate bone metabolism through essential roles in the formation, activation, and survival of osteoclasts [2]. In addition, OPG plays an important role in atherosclerosis, arterial calcification, and vascular disease [3]. OPG is highly expressed in the liver, kidney, bone marrow, and other tissues and produced by a variety of cell types including endothelial cells and smooth muscle cells [4]. Clinical studies indicate that serum OPG concentrations are associated with coronary artery disease, vascular calcification, diabetic complications, and cardiovascular mortality [5-7]. Recent studies suggest that OPG may be a new marker for diabetic cardiovascular complications and atherosclerosis [8].

Elevated concentrations of OPG have been reported in diabetic individuals and were independently associated with the diabetic microvascular complications [9]. However, the serum OPG concentrations in individuals with prediabetes, such as impaired glucose tolerance, have rarely been studied. We hypothesized that serum OPG levels might be increased 
at the stage of prediabetes, and serum OPG may be a potential biomarker in diabetes and prediabetes. Therefore, we conducted a study to investigate the changes in serum levels of OPG in Chinese postmenopausal women with diabetes and prediabetes and explore the relationships between serum OPG and insulin resistance, body mass index, lipid profile, and blood glucose.

\section{Subjects and Methods}

2.1. Study Population. A total of 271 unrelated southern Han Chinese postmenopausal women were recruited from the database of our previous female osteoporosis study [10] from February 1, 2013, to November 30, 2013. Standard oral glucose tolerance testing was performed in all the subjects except those who had already been diagnosed with type 2 diabetes. The subjects were divided into type 2 diabetes (T2DM) group $(n=93)$, impaired glucose regulation (IGR) group $(n=90)$, and normal glucose regulation (NGR) group $(n=88)$, according to different glucose regulation categories.

Diabetes was defined using the World Health Organization 1999 criteria: (1) fasting plasma glucose (FPG) $\geq 7.0 \mathrm{mmol} / \mathrm{L}$ or (2) $2 \mathrm{~h}$ postprandial plasma glucose ( $2 \mathrm{hPG}$ ) in oral glucose tolerance test $\geq 11.1 \mathrm{mmol} / \mathrm{L}$ or (3) typical symptoms with random plasma glucose $\geq 11.1 \mathrm{mmol} / \mathrm{L}$. Impaired glucose regulation, also termed as prediabetes, was defined as follows: $6.1 \mathrm{mmol} / \mathrm{L} \leq \mathrm{FPG}<7.0 \mathrm{mmol} / \mathrm{L}$ and/or $7.8 \mathrm{mmol} / \mathrm{L} \leq 2 \mathrm{hPG}<11.1 \mathrm{mmol} / \mathrm{L}$. The criteria for normal glucose regulation were defined as follows: $\mathrm{FPG}<6.1 \mathrm{mmol} / \mathrm{L}$ and $2 \mathrm{hPG}<7.8 \mathrm{mmol} / \mathrm{L}$.

Exclusion criteria included subjects who suffered from diseases associated with disordered glucose metabolism, such as chronic liver disease, severe kidney disease, hypothyroidism, and pituitary or adrenal diseases. Participants who had taken glucocorticosteroid or bisphosphonates within the past 3 months and had a fracture within 1 year were also excluded. In the study, 12 participants had taken calcium and/or vitamin $\mathrm{D}$. In the diabetes group, the average duration of diabetes was $4.0 \pm 4.5$ years, 55 individuals were newly diagnosed with diabetes without any medication, 2 patients were treated with insulin, and 36 patients were treated with oral hypoglycemic agents, such as metformin, sulfonylureas, and acarbose, but no thiazolidinediones.

Demographic information was collected by an interview through a questionnaire, such as age, smoking history, alcohol intake, and a detailed medical history, especially the history of diabetes. The study was approved by the ethics committee of the Third Hospital of Nanchang, and the subjects provided written informed consent before participation in the study.

2.2. Anthropometric Measurements. Height and weight were measured to the nearest $1 \mathrm{~cm}$ and $0.1 \mathrm{~kg}$, respectively. Body mass index (BMI) was calculated [formula: BMI = body weight $(\mathrm{kg}) /$ height $\left.^{2}\left(\mathrm{~m}^{2}\right)\right]$. Waist circumference and hip circumference (to the nearest $1 \mathrm{~cm}$ ) were measured, and waist-to-hip ratio (WHR) was calculated [formula: WHR = waist circumference $(\mathrm{cm}) /$ hip circumference $(\mathrm{cm})]$. Blood pressure and pulse rates were measured in the sitting position using electronic sphygmomanometer Omron, HEM-7200 (Omron Inc., Tokyo, Japan). Body fat percentage was detected using electronic body fat measuring instrument Omron, HBF-375 (Omron Inc., Tokyo, Japan). Bone mineral densities at the lumbar spine $\left(\mathrm{L}_{2}-\mathrm{L}_{4}\right)$ and femoral neck were measured by dual X-ray absorptiometry (DXA, GE-Lunar Prodigy, Waukesha, WI, USA).

2.3. Biochemical Assays. Blood samples were taken after an overnight fast. Measurements of serum biochemical parameters, such as FPG, 2hPG, alanine aminotransferase (ALT), aspartate aminotransferase (AST), alkaline phosphatase (ALP), blood urea nitrogen (BUN), creatinine (Cr), high-density lipoprotein cholesterol (HDL-C), low-density lipoprotein cholesterol (LDL-C), total cholesterol (TC), triglycerides (TG), and blood uric acid (URCA), were performed using commercially available kits (Siemens Inc., Erlangen, Germany) on the day of the collection. Subsequently, serum was separated, stored at $-80^{\circ} \mathrm{C}$, until OPG analysis. Serum insulin was measured using an electrochemiluminescence immunoassay (Roche Diagnostics, Indianapolis, USA), while glycated hemoglobin (HbA1c) was detected by high-performance liquid chromatography (Bio-Rad Inc., CA, USA). Serum OPG levels were measured by enzyme-linked immunosorbent assay kit (RayBiotech, Norcross, GA, USA). All of the samples were assayed blindly, in duplicate, and in random order. The sensitivity of the kit was minimally $1 \mathrm{pg} / \mathrm{mL}$ and the mean intra- and interassay coefficients of variation were below $10 \%$.

Insulin resistance was determined by homeostasis model assessment (HOMA-IR), and HOMA-IR index was calculated [formula: fasting plasma glucose $(\mathrm{mmol} / \mathrm{L}) \times$ fasting serum insulin $(\mathrm{mU} / \mathrm{mL}) / 22.5]$. According to previous studies, HOMA-IR index $>1.8$ has been suggested as a cut-off point to indicate increased insulin resistance [11]. The homeostasis model assessment of $\beta$-cell function (HOMA-B) (\%) was calculated using the formula: HOMA-B $=(20 \times$ fasting insulin)/(fasting glucose-3.5) [12]. The quantitative insulinsensitivity check index (QUICKI) was estimated according to the formula: QUICKI $=1 /[\log$ (fasting insulin in $\mathrm{mU} /$ $\mathrm{mL})+\log ($ fasting glucose in $\mathrm{mg} / \mathrm{dl})]$ [13]. The abbreviated MDRD equation was used to estimate glomerular filtration rate $(\mathrm{eGFR})$ as $186 \times$ [plasma creatinine ${ }^{-1.154}$ ] $\times(\text { age })^{-0.203} \times$ (0.742 if female) [14].

2.4. Statistical Analysis. Data are reported as means \pm standard deviation or median (25th-75th percentile). SPSS 19.0 (SPSS Inc., Chicago, IL, USA) was used to perform the statistical analysis. Normality was tested for via the KolmogorovSmirnov test and if violated, a natural logarithmic transformation (e.g., HOMA-IR) was used where possible. Statistical comparisons between groups were made using one-way ANOVA with post hoc comparisons for normally distributed variables [15]. For non-normally distributed variables (e.g., HbAlc, HOMA-IR), nonparametric comparisons were made using Kruskal-Wallis test. The statistical differences in means of average serum OPG levels between each group were determined by analysis of covariance, which was adjusted for the confounding factors in different models. The bivariate 
TABLE 1: Clinical and biochemical characteristics of the study subjects.

\begin{tabular}{|c|c|c|c|}
\hline Variable & $\begin{array}{l}\text { NGR group } \\
(n=88)\end{array}$ & $\begin{array}{l}\text { IGR group } \\
(n=90)\end{array}$ & $\begin{array}{l}\text { T2DM group } \\
(n=93)\end{array}$ \\
\hline Age (year) & $62.83 \pm 8.57$ & $62.38 \pm 9.02$ & $63.81 \pm 8.69$ \\
\hline SBP (mmHg) & $138.40 \pm 20.76$ & $141.80 \pm 19.54$ & $147.62 \pm 21.06^{\mathrm{a}}$ \\
\hline $\mathrm{DBP}(\mathrm{mmHg})$ & $80.06 \pm 13.61$ & $80.9 \pm 12.43$ & $80.97 \pm 12.93$ \\
\hline Pulse rates (beats/min) & $87 \pm 13$ & $88 \pm 13$ & $87 \pm 11$ \\
\hline Height $(\mathrm{cm})$ & $153.10 \pm 5.50$ & $154.03 \pm 6.28$ & $153.71 \pm 6.23$ \\
\hline Weight $(\mathrm{kg})$ & $57.24 \pm 9.25$ & $60.36 \pm 10.41^{\mathrm{a}}$ & $60.80 \pm 8.59^{\mathrm{a}}$ \\
\hline BMI $\left(\mathrm{kg} / \mathrm{m}^{2}\right)$ & $24.40 \pm 3.56$ & $25.38 \pm 3.67$ & $25.70 \pm 3.06^{\mathrm{a}}$ \\
\hline Waist circumference $(\mathrm{cm})$ & $77.33 \pm 9.16$ & $79.84 \pm 9.38$ & $81.95 \pm 8.86^{\mathrm{a}}$ \\
\hline Hip circumference $(\mathrm{cm})$ & $91.98 \pm 7.78$ & $92.53 \pm 8.99$ & $93.51 \pm 7.84$ \\
\hline Waist-to-hip ratio & $0.84 \pm 0.06$ & $0.86 \pm 0.06^{\mathrm{a}}$ & $0.88 \pm 0.06^{\mathrm{a}}$ \\
\hline Body fat percentage (\%) & $37.34 \pm 3.66$ & $37.69 \pm 4.11$ & $37.81 \pm 3.84$ \\
\hline $\operatorname{ALT}(\mathrm{U} / \mathrm{L})$ & $22.0(17.0-22.8)$ & $28.0(21.0-41.3)^{\mathrm{a}}$ & $27.0(17.5-42.0)^{\mathrm{a}}$ \\
\hline $\operatorname{AST}(\mathrm{U} / \mathrm{L})$ & $28.0(24.0-35.5)$ & $30.0(23.8-34.0)$ & $26.0(21.0-34.5)$ \\
\hline $\operatorname{ALP}(\mathrm{U} / \mathrm{L})$ & $77.0(64.8-92.8)$ & $82.0(65.8-96.5)$ & $82.0(70.0-96.0)$ \\
\hline $\mathrm{BUN}(\mathrm{mmol} / \mathrm{L})$ & $4.76(4.03-5.81)$ & $4.67(3.82-5.41)$ & $5.03(4.02-5.98)$ \\
\hline $\mathrm{Cr}(\mu \mathrm{mol} / \mathrm{L})$ & $62.0(69.0-77.0)$ & $70.0(61.8-77.0)$ & $67.0(60.0-78.0)$ \\
\hline URCA $(\mu \mathrm{mol} / \mathrm{L})$ & $282.0(243.8-334.0)$ & $316.5(283.8-376.5)^{\mathrm{a}}$ & $312.0(263.5-363.5)^{\mathrm{a}}$ \\
\hline $\mathrm{TC}(\mathrm{mmol} / \mathrm{L})$ & $5.38 \pm 1.13$ & $5.62 \pm 1.14$ & $5.81 \pm 1.52^{\mathrm{a}}$ \\
\hline $\mathrm{TG}(\mathrm{mmol} / \mathrm{L})$ & $1.07(0.85-1.34)$ & $1.34(1.08-1.85)^{\mathrm{a}}$ & $1.40(1.05-1.93)^{\mathrm{a}}$ \\
\hline HDL-C (mmol/L) & $1.58(1.38-1.91)$ & $1.47(1.32-1.73)$ & $1.41(1.26-1.63)^{\mathrm{a}}$ \\
\hline LDL-C (mmol/L) & $2.94(2.64-3.48)$ & $3.24(2.81-3.75)$ & $3.22(2.71-3.70)$ \\
\hline $\mathrm{FPG}(\mathrm{mmol} / \mathrm{L})$ & $4.60(4.18-4.90)$ & $5.19(4.99-5.89)^{\mathrm{a}}$ & $6.16(6.89-8.98)^{\mathrm{a}, \mathrm{b}}$ \\
\hline $2 \mathrm{hPG}(\mathrm{mmol} / \mathrm{L})$ & $5.62(4.82-6.22)$ & $8.52(7.98-9.53)^{\mathrm{a}}$ & $13.46(11.61-16.77)^{\mathrm{a}, \mathrm{b}}$ \\
\hline HbAlc (\%) & $5.5(5.4-5.7)$ & $6.0(5.6-6.3)^{\mathrm{a}}$ & $7.4(6.1-8.0)^{\mathrm{a}, \mathrm{b}}$ \\
\hline FINS (mIU/L) & $8.00(4.94-11.18)$ & $11.55(7.25-15.48)^{\mathrm{a}}$ & $10.99(7.39-15.34)^{\mathrm{a}}$ \\
\hline HOMA-IR index & $1.54(1.02-2.22)$ & $2.39(1.80-3.78)^{\mathrm{a}}$ & $3.48(2.33-5.06)^{\mathrm{a}, \mathrm{b}}$ \\
\hline HOMA-B & $155.60(86.03-253.09)$ & $126.30(76.02-222.09)$ & $64.27(40.22-107.40)^{\mathrm{a}, \mathrm{b}}$ \\
\hline QUICKI & $0.362 \pm 0.032$ & $0.334 \pm 0.034^{\mathrm{a}}$ & $0.319 \pm 0.027^{\mathrm{a}, \mathrm{b}}$ \\
\hline Lumbar BMD $\left(\mathrm{mg} / \mathrm{cm}^{2}\right)$ & $0.866 \pm 0.173$ & $0.903 \pm 0.168$ & $0.937 \pm 0.146^{\mathrm{a}}$ \\
\hline Femoral neck BMD $\left(\mathrm{mg} / \mathrm{cm}^{2}\right)$ & $1.006 \pm 0.174$ & $1.053 \pm 0.186$ & $1.074 \pm 0.155^{\mathrm{a}}$ \\
\hline Serum OPG (pg/mL) & $151.00 \pm 45.72$ & $169.28 \pm 64.91^{\mathrm{a}}$ & $183.20 \pm 56.53^{\mathrm{a}}$ \\
\hline eGFR & $81.98 \pm 17.61$ & $80.96 \pm 18.84$ & $81.72 \pm 18.47$ \\
\hline Smoking history (\%) & $1(1.14)$ & $2(2.22)$ & $2(2.15)$ \\
\hline Alcohol intake (\%) & $3(3.41)$ & $3(3.33)$ & $2(2.15)$ \\
\hline Calcium and vitamin D supplements (\%) & $3(3.41)$ & $5(5.56)$ & $4(4.30)$ \\
\hline
\end{tabular}

Data are presented as means \pm SD or median (25th-75th percentile). ${ }^{\mathrm{a}} p<0.05$ versus NGT group; ${ }^{\mathrm{b}} p<0.05$ versus IGR group.

$2 \mathrm{hPG}, 2 \mathrm{~h}$ postprandial plasma glucose; ALP, alkaline phosphatase; ALT, alanine aminotransferase; AST, aspartate aminotransferase; BMD, bone mineral density; BMI, body mass index; BUN, blood urea nitrogen; Cr, creatinine; eGFR, estimate glomerular filtration rate; FINS, fasting insulin; FPG, fasting plasma glucose; HbAlc, glycated hemoglobin; HDL-C, high-density lipoprotein cholesterol; HOMA-B, homeostasis model assessment of $\beta$-cell function; HOMA-IR, homeostasis model of assessment for insulin resistance; IGR, impaired glucose regulation; LDL-C, low-density lipoproteincholesterol; NGR, normal glucose regulation; OPG, osteoprotegerin; QUICKI, quantitative insulin sensitivity check index; SBP, systolic blood pressure; DBP, diastolic blood pressure; T2DM, type 2 diabetes; TC, total cholesterol; TG, triglycerides; URCA, blood uric acid.

correlations between OPG and other parameters were determined by Spearman's correlation analysis. Stepwise multilinear regression analysis was performed in order to study the independent variables that may affect OPG values. Logistic regression was used to assess the association between insulin resistance and serum parameters (e.g., OPG, TC, and TG) and other potential independent variables (e.g., age, BMI, and HbA1c). Statistical significance is defined as a $p$ value $<0.05$ on two-tailed testing.

\section{Results}

3.1. Characteristics of Participants. The basic characteristics of T2DM group $(n=93)$, IGR group $(n=90)$, and NGR 
TABLE 2: Comparsion of serum osteoprotegerin levels with different glucose regulation.

\begin{tabular}{lccccc}
\hline Model & $\begin{array}{c}\text { NGR group } \\
(n=88)\end{array}$ & $\begin{array}{c}\text { Serum osteoprotegerin }(\mathrm{pg} / \mathrm{mL}) \\
\text { IGR group } \\
(n=90)\end{array}$ & $\begin{array}{c}\text { T2DM group } \\
(n=93)\end{array}$ & $p$ value $^{\mathrm{d}}$ & $p$ \\
\hline Model 1 $^{\mathrm{a}}$ & $151.00 \pm 4.87$ & $169.28 \pm 6.84$ & $183.20 \pm 5.86$ & 0.031 & $<0.001$ \\
Model 2 $^{\mathrm{b}}$ & $153.69 \pm 5.33$ & $170.75 \pm 5.19$ & $179.23 \pm 5.16$ & 0.023 & 0.001 \\
Model 3 $^{\mathrm{c}}$ & $154.54 \pm 5.24$ & $170.61 \pm 5.05$ & $178.56 \pm 4.98$ & 0.031 & 0.096 \\
\hline
\end{tabular}

Serum OPG data is presented as means \pm SE. IGR, impaired glucose regulation; NGR, normal glucose regulation; T2DM, type 2 diabetes.

${ }^{\mathrm{a}}$ Unadjusted; 'bdjusted for age, body mass index, waist-to-hip ratio, and body fat percentage; ${ }^{\mathrm{c}}$ adjusted for age, body mass index, waist-to-hip ratio, body fat percentage, eGFR, blood uric acid, aspartate aminotransferase, and alkaline phosphatase; ${ }^{\mathrm{d}} \mathrm{NGT}$ group versus IGR group; ${ }^{\mathrm{e}} \mathrm{NGT}$ group versus T2DM group; ${ }_{\mathrm{f}}^{\mathrm{IGR}}$ group versus T2DM group.

group $(n=88)$ were shown in Table 1 . There was no significant difference in age, DBP, pulse rates, height, hip circumference, body fat percentage, AST, BNU, Cr, eGFR, and LDL-C between these groups (all $p>0.05$ ). The serum OPG concentration in NGR group, $151.00 \pm 45.72 \mathrm{pg} / \mathrm{mL}$, was significantly lower than that in IGR group $(169.28 \pm 64.91 \mathrm{pg} / \mathrm{mL})$ $(p=0.031)$ and T2DM group $(183.20 \pm 56.53 \mathrm{pg} / \mathrm{mL})$ $(p<0.001)$, respectively. The serum OPG level in IGR group was lower than T2DM group, although there was no statistically significant difference $(p=0.096)$. The serum OPG levels in IGR group and T2DM group are still higher than that in NGR group even after adjustment for other confounding factors in different models (Table 2). In addition, the weight, waist-to-hip ratio, ALT, URCA, TG, FPG, 2hPG, FINS, HbA1c, HOMA-IR, and lumbar and femoral neck BMD in IGR and T2DM groups were significantly higher than those in NGR group (all $p<0.05$ ).

3.2. Relationship between Serum OPG Levels and Clinical Parameters. Bivariate correlation analysis of serum OPG levels with clinical parameters was performed (Table 3). Serum OPG levels showed a significantly positive correlation with HOMA-IR $(r=0.134, p=0.027)$, waist-to-hip ratio, body fat percentage, ALP, $2 \mathrm{hPG}$, and HbAlc (all $p<0.05$ ) but significantly negative correlation with lumbar and femoral neck BMD $(p=0.002$ and $p=0.032)$.

In stepwise multiple linear regression analysis with OPG as a dependent variable, age, body fat percentage, waist-tohip ratio, BMI, SBP, DBP, ALT, AST, ALP, eGFR, TC, TG, HDL-C, LDL-C, 2hPG, HbA1c, and HOMA-IR were added to the model. Finally, HOMA-IR, age, 2hPG, AST, ALP, and eGFR were found to be independent predictors of serum OPG (all $p<0.05)$ (Table 4$)$.

In logistic regression analyses with insulin resistance as the dependent variable, OPG, BMI, ALT, URCA, HDL-C, LDL-C, and HbAlc were significantly associated with insulin resistance (all $p<0.05$ ). As shown in Table 5, increased serum OPG levels $(\mathrm{OR}=1.009$, CI 95\% $=1.003-$ $1.015, p=0.006)$ may be a risk factor for insulin resistance in postmenopausal women.

\section{Discussion}

In the present study, we demonstrated that circulating OPG concentrations were increased in Chinese postmenopausal women with diabetes and prediabetes. Moreover, serum OPG levels showed significant correlation with insulin resistance.

HOMA-IR was used as a surrogate measure of insulin resistance in our study. Although HOMA-IR was not the gold standard for assessment of insulin sensitivity, it was a clinically useful index used in many studies [16]. Population-based studies for defining cut-off values of HOMA-IR for the diagnosis of insulin resistance have been conducted in different geographic areas. At present, there is no national survey data about the cut-off values of HOMA-IR in Chinese population. Thus, we defined HOMA-IR index $>1.8$ as a cut-off point to indicate increased insulin resistance according to previous studies [11, 17, 18]. Studies have indicated that there are age and genderspecific differences in HOMA-IR levels, with increased levels in women over fifty years of age. Although the cut-off point 1.8 may not be suitable for the Chinese population, it can provide a useful reference point for our study when there is no available data for the Chinese population.

Previous reports had reported similar results about the association between serum OPG levels and HOMA-IR in subjects with type 2 diabetes mellitus [19] and Caucasian obese population [20]. In contrast, several studies have shown a negative association between OPG and HOMA-IR in obese African women [21] and Turkish population [22]. Besides, two studies in healthy Korean women and Irish population did not find any relationship between these two parameters $[23,24]$. This result has long been a matter of controversy in the literature, possibly because of different methodologies and sample sizes of the study populations. Our findings are in line with a recent report by Niu et al. [25]; the authors found serum OPG levels were significantly associated with HOMA-IR in Chinese population, and serum OPG levels were significantly higher in subjects with impaired glucose regulation and diabetes than in those with normal glucose regulation.

OPG could be produced by a variety of cells of the cardiovascular system, including vascular smooth muscle cells and endothelial cells, and OPG represents a protective factor for vascular system [26]. For example, OPG has been reported to increase cell proliferation of human artery and vein endothelial cells, maybe via inducing phosphorylation of extracellular signal-regulated kinases $1 / 2$ and protein kinase B in those cells, which are similar to the effects of those growth factors such as fibroblast growth factor and vascular endothelial growth factor in the endothelial cells [27-30]. It 
TABLE 3: Bivariate correlation analysis between study parameters and serum osteoprotegerin levels.

\begin{tabular}{|c|c|c|}
\hline \multirow{2}{*}{ Parameters } & \multicolumn{2}{|c|}{ Bivariate correlation } \\
\hline & $r$ & $p$ value \\
\hline Age & 0.453 & $<0.001$ \\
\hline Height & -0.115 & 0.058 \\
\hline Weight & -0.082 & 0.178 \\
\hline BMI & -0.036 & 0.552 \\
\hline Waist circumference & 0.078 & 0.203 \\
\hline Hip circumferences & -0.005 & 0.793 \\
\hline Waist-to-hip ratio & 0.125 & 0.039 \\
\hline Body fat percentage & 0.213 & $<0.001$ \\
\hline ALT & -0.014 & 0.823 \\
\hline AST & 0.086 & 0.157 \\
\hline ALP & 0.175 & 0.004 \\
\hline BUN & 0.025 & 0.688 \\
\hline $\mathrm{Cr}$ & 0.193 & 0.001 \\
\hline Calcium & -0.001 & 0.981 \\
\hline URCA & 0.046 & 0.451 \\
\hline TC & -0.006 & 0.924 \\
\hline TG & 0.027 & 0.660 \\
\hline HDL-C & 0.012 & 0.847 \\
\hline LDL-C & -0.077 & 0.207 \\
\hline FPG & 0.093 & 0.133 \\
\hline $2 \mathrm{hPG}$ & 0.270 & $<0.001$ \\
\hline $\mathrm{HbAlc}$ & 0.214 & $<0.001$ \\
\hline FINS & 0.106 & 0.080 \\
\hline Ln HOMA-IR & 0.134 & 0.027 \\
\hline HOMA-B & -0.037 & 0.546 \\
\hline QUICKI & -0.194 & 0.001 \\
\hline eGFR & -0.331 & $<0.001$ \\
\hline Lumbar BMD & -0.189 & 0.002 \\
\hline Femoral neck BMD & -0.130 & 0.032 \\
\hline
\end{tabular}

$2 \mathrm{hPG}, 2 \mathrm{~h}$ postprandial plasma glucose; ALP, alkaline phosphatase; ALT, alanine aminotransferase; AST, aspartate aminotransferase; BMD, bone mineral density; BMI, body mass index; BUN, blood urea nitrogen; $\mathrm{Cr}$, creatinine; eGFR, estimate glomerular filtration rate; FINS, fasting insulin; FPG, fasting plasma glucose; HbA1c, glycated hemoglobin; HDL-C, highdensity lipoprotein cholesterol; HOMA-B, homeostasis model assessment of $\beta$-cell function; LDL-C, low-density lipoproteincholesterol; Ln HOMAIR, natural logarithmic transformation homeostasis model of assessment for insulin resistance index; OPG, osteoprotegerin; QUICKI, quantitative insulin sensitivity check index; SBP, systolic blood pressure; SDP, diastolic blood pressure; TC, total cholesterol; TG, triglycerides; URCA, blood uric acid.

is suggested that increased serum OPG levels in subjects with diabetes have been interpreted as an insufficient compensatory self-defensive response to prevent vascular endothelial dysfunction and the progression of atherosclerosis [31]. Thus, some studies suggest that increased OPG production represents an early event in the natural history of diabetes, possibly contributing to diabetes-associated vascular endothelial cell dysfunction [32].

In our study, serum OPG levels showed significant association with insulin resistance, but the mechanisms
TABLE 4: Multiple linear regression analysis with osteoprotegerin as a dependent variable.

\begin{tabular}{lcc}
\hline Parameters & $\beta$ & $p$ value \\
\hline Age & 2.747 & $<0.001$ \\
HOMA-IR & 2.591 & 0.024 \\
eGFR & -0.457 & 0.010 \\
AST & 0.575 & 0.001 \\
ALP & 0.362 & 0.003 \\
2hPG & 2.289 & 0.001 \\
\hline
\end{tabular}

2hPG, $2 \mathrm{~h}$ postprandial plasma glucose; ALP, alkaline phosphatase; AST, aspartate aminotransferase; eGFR, estimate glomerular filtration rate; HOMA-IR, homeostasis model of assessment for insulin resistance.

TABLE 5: Stepwise logistic regression analysis with insulin resistance as a dependent variable.

\begin{tabular}{lccc}
\hline Parameters & Odds ratio & 95\% confidence interval & $p$ value \\
\hline OPG & 1.009 & $1.003-1.015$ & 0.006 \\
BMI & 1.238 & $1.112-1.378$ & $<0.001$ \\
URCA & 1.005 & $1.001-1.010$ & 0.020 \\
HDL-C & 0.351 & $0.132-0.930$ & 0.035 \\
LDL-C & 1.724 & $1.162-2.558$ & 0.007 \\
HbAlc & 2.048 & $1.368-3.065$ & 0.001 \\
ALT & 1.024 & $1.005-1.043$ & 0.012 \\
\hline
\end{tabular}

ALT, alanine aminotransferase; BMI, body mass index; HbAlc, glycated hemoglobin; HDL-C, high-density lipoprotein cholesterol; LDL-C, lowdensity lipoproteincholesterol; OPG, osteoprotegerin; URCA, blood uric acid.

underlying the association are currently unclear. It is thought that inflammation may link OPG to insulin resistance. Insulin resistance is a hallmark of type 2 diabetes mellitus and regarded as a chronic low-grade systemic inflammation [33]. It has been demonstrated that OPG was positively correlated with inflammatory markers and played a causal role in the pathogenesis of inflammation [34]. OPG/RANK/ RANKL system is believed to be associated with the regulation of inflammatory and immune responses and directly contributed to the regulation of proinflammatory cytokine production in macrophages [35]. Additionally, it is well established that the OPG/RANK/RANKL system could activate the NF- $\kappa \mathrm{B}$ pathway and its downstream players [36], which are closely related to the pathogenesis of insulin resistance [37]. Thus, OPG may have a role in insulin resistance through NF- $\kappa$ B pathway. Recently, evidence has indicated that the OPG/RANK/RANKL system may have a potential role in the pathogenesis of diabetes; blocking this pathway improved hepatic insulin resistance and prevented the development of diabetes mellitus [38].

It has been recognized that the OPG is a cytokine that increases the mineral density and volume of bone tissue by decreasing the number of active osteoclasts. In our study, bivariate analysis showed an inverse correlation between OPG levels and BMD in postmenopausal women. The result was teleologically interpreted as a counter-regulatory mechanism in order to prevent further bone loss. A significantly negative correlation between circulating levels of OPG and 
BMD was also reported in two studies in patients with type 1 and 2 diabetes mellitus $[39,40]$. However, a positive correlation between serum levels of OPG and BMD was found in postmenopausal women by Nabipour et al. [41]. In addition, several other studies have not demonstrated an association between serum OPG concentration and BMD [42]. The reason for these conflicting results is unclear but may lie in differences in populations or assays studied or in incomplete control for confounding variables.

Additionally, we found serum OPG levels were positively correlated with age, 2hPG, HbAlc, AST, ALP, and eGFR through linear regression analysis. These findings were consistent with evidences from previous studies that found serum OPG levels were associated with several clinical and biochemical parameters [43]. The increasing serum concentrations of OPG with aging could be explained by a compensatory mechanism to counteract the acceleration of bone resorption [44]. Serum OPG levels were significantly associated with AST, ALP, and eGFR, which were the markers of liver and renal function, and these results may be interpreted as follows: OPG was highly expressed in the liver and kidney, and there were significant associations between high OPG serum levels and liver and kidney dysfunctions [45, 46]. The serum OPG was significantly increased in patients with chronic kidney disease. Recent evidences suggest that inflammation, secondary hyperparathyroidism, disorder of bone metabolism, vascular calcifications, and atherosclerosis may play important roles in this process [47].

The main limitation of our study is small sample size; our current findings need to be confirmed in further large population studies. In addition, serum OPG concentrations are gender-specific; for example, women have higher circulating OPG levels than men. We conducted a study in a select group of Chinese postmenopausal women, and the subjects were recruited from the database of our previous female osteoporosis study. Thus, future researches in randomly selected and different gender population are needed. Furthermore, the exact mechanisms underlying the observed associations in this study remain to be determined.

\section{Conclusions}

The current study demonstrates that serum OPG level is elevated in postmenopausal women with diabetes and prediabetes and significantly associated with insulin resistance. These findings suggest that OPG might be implicated in the pathogenesis of diabetes and is a potential biomarker of insulin resistance in subjects with diabetes and prediabetes.

\section{Competing Interests}

The authors have declared no competing interests.

\section{Authors' Contributions}

Peng Duan and Min Yang contributed equally to this work.

\section{Acknowledgments}

This work was supported by the National Natural Science Foundation of China (no. 81260133) and the Jiangxi Province Science Foundation for Youths (no. 20151BAB215012).

\section{References}

[1] T. J. Martin and N. A. Sims, "RANKL/OPG; critical role in bone physiology," Reviews in Endocrine \& Metabolic Disorders, vol. 16, no. 2, pp. 131-139, 2015.

[2] W. Liu and X. Zhang, "Receptor activator of nuclear factor- $\kappa B$ ligand (RANKL)/RANK/osteoprotegerin system in bone and other tissues," Molecular Medicine Reports, vol. 11, no. 5, pp. 3212-3218, 2015.

[3] A. Augoulea, N. Vrachnis, I. Lambrinoudaki et al., "Osteoprotegerin as a marker of atherosclerosis in diabetic patients," International Journal of Endocrinology, vol. 2013, Article ID 182060, 6 pages, 2013.

[4] A. Esteghamati, M. Aflatoonian, M. V. Rad et al., "Association of osteoprotegerin with peripheral artery disease in patients with type 2 diabetes," Archives of Cardiovascular Diseases, vol. 108, no. 8, pp. 412-419, 2015.

[5] C. Pérez de Ciriza, A. Lawrie, and N. Varo, "Osteoprotegerin in cardiometabolic disorders," International Journal of Endocrinology, vol. 2015, Article ID 564934, 15 pages, 2015.

[6] J. R. Lewis, W. H. Lim, T. Ueland et al., "Elevated circulating osteoprotegerin and renal dysfunction predict 15-year cardiovascular and all-cause mortality: a prospective study of elderly Women," PLoS ONE, vol. 10, no. 7, Article ID e0134266, 2015.

[7] T. Morisawa, A. Nakagomi, K. Kohashi et al., "Osteoprotegerin is associated with endothelial function and predicts early carotid atherosclerosis in patients with coronary artery disease," International Heart Journal, vol. 56, no. 6, pp. 605612, 2015.

[8] I. Lambrinoudaki, E. Tsouvalas, M. Vakaki et al., "Osteoprotegerin, soluble receptor activator of nuclear factor $-\kappa \mathrm{B}$ ligand, and subclinical atherosclerosis in children and adolescents with type 1 diabetes mellitus," International Journal of Endocrinology, vol. 2013, Article ID 102120, 8 pages, 2013.

[9] A. M. Blázquez-Medela, J. M. López-Novoa, and C. Martínez-Salgado, "Osteoprotegerin and diabetes-associated pathologies," Current Molecular Medicine, vol. 11, no. 5, pp. 401-416, 2011.

[10] P. Tu, P. Duan, R. S. Zhang et al., "Polymorphisms in genes in the RANKL/RANK/OPG pathway are associated with bone mineral density at different skeletal sites in postmenopausal women," Osteoporosis International, vol. 26, no. 1, pp. 179-185, 2015.

[11] R. E. Maser, M. J. Lenhard, M. B. Sneider, and R. T. Pohlig, "Osteoprotegerin is a better serum biomarker of coronary artery calcification than osteocalcin in type 2 diabetes," Endocrine Practice, vol. 21, no. 1, pp. 14-22, 2015.

[12] D. R. Matthews, J. P. Hosker, A. S. Rudenski, B. A. Naylor, D. F. Treacher, and R. C. Turner, "Homeostasis model assessment: insulin resistance and $\beta$-cell function from fasting plasma glucose and insulin concentrations in man," Diabetologia, vol. 28, no. 7, pp. 412-419, 1985.

[13] A. Katz, S. S. Nambi, K. Mather et al., "Quantitative insulin sensitivity check index: a simple, accurate method for assessing insulin sensitivity in humans," The Journal of Clinical Endocrinology \& Metabolism, vol. 85, no. 7, pp. 2402-2410, 2000. 
[14] A. S. Levey, J. P. Bosch, J. B. Lewis, T. Greene, N. Rogers, and D. Roth, "A more accurate method to estimate glomerular filtration rate from serum creatinine: a new prediction equation. Modification of Diet in Renal Disease Study Group," Annals of Internal Medicine, vol. 130, no. 6, pp. 461-470, 1999.

[15] Y. Li, K. Wang, Q. Y. Zou, R. R. Magness, and J. Zheng, "2,3,7,8-Tetrachlorodibenzo-p-dioxin differentially suppresses angiogenic responses in human placental vein and artery endothelial cells," Toxicology, vol. 336, pp. 70-78, 2015.

[16] A. F. Cicero, M. Rosticci, A. Parini et al., "Short-term effects of a combined nutraceutical of insulin-sensitivity, lipid level and indexes of liver steatosis: a double-blind, randomized, cross-over clinical trial," Nutrition Journal, vol. 2015, no. 14, article 30, 2015.

[17] A. Esteghamati, H. Ashraf, A. R. Esteghamati et al., "Optimal threshold of homeostasis model assessment for insulin resistance in an Iranian population: the implication of metabolic syndrome to detect insulin resistance," Diabetes Research and Clinical Practice, vol. 84, no. 3, pp. 279-287, 2009.

[18] P. Gayoso-Diz, A. Otero-González, M. X. Rodriguez-Alvarez, F. García, A. De Francisco, and A. G. Quintela, "Insulin resistance (HOMA-IR) cut-off values and the metabolic syndrome in a general adult population: effect of gender and age: EPIRCE cross-sectional study," BMC Endocrine Disorders, vol. 2013, no. 13, article 47, 2013.

[19] S. Yaturu, J. Rains, and S. K. Jain, "Relationship of elevated osteoprotegerin with insulin resistance, CRP, and TNF-alpha levels in men with type 2 diabetes," Cytokine, vol. 44 , no. 1 , pp. 168-171, 2008.

[20] M. H. Gannagé-Yared, C. Yaghi, B. Habre et al., "Osteoprotegerin in relation to body weight, lipid parameters, insulin sensitivity, adipocytokines, and C-reactive protein in obese and non-obese young individuals: results from both crosssectional and interventional study," European Journal of Endocrinology, vol. 158, no. 3, pp. 353-359, 2008.

[21] C. N. Ayina Ayina, E. Sobngwi, M. Essouma et al., "Osteoprotegerin in relation to insulin resistance and blood lipids in sub-Saharan African women with and without abdominal obesity," Diabetology \& Metabolic Syndrome, vol. 2015, no. 7, article 47, 2015.

[22] B. Ugur-Altun, A. Altun, M. Gerenli, and A. Tugrul, "The relationship between insulin resistance assessed by HOMA-IR and serum osteoprotegerin levels in obesity," Diabetes Research and Clinical Practice, vol. 68, no. 3, pp. 217-222, 2005.

[23] E. S. Oh, E. J. Rhee, K. W. Oh et al., "Circulating osteoprotegerin levels are associated with age, waist-to-hip ratio, serum total cholesterol, and low-density lipoprotein cholesterol levels in healthy Korean women," Metabolism, vol. 54, no. 1, pp. 49-54, 2005.

[24] E. P. O’Sullivan, D. T. Ashley, C. Davenport et al., "A comparison of osteoprotegerin with adiponectin and high-sensitivity C-reactive protein (hsCRP) as a marker for insulin resistance," Metabolism, vol. 54, no. 1, pp. 34-38, 2013.

[25] Y. Niu, Z. Yang, X. Li et al.S. Lu, H. Zhang, X. Chen et al., "Association of osteoprotegerin with impaired glucose regulation and microalbuminuria: the REACTION study," $B M C$ Endocrine Disorders, vol. 2015, no. 15, article 75, 2015.

[26] H. H. Wang and G. D. Xiang, "Changes of plasma concentration of osteoprotegerin and its association with endothelial dysfunction before and after hypouricemic therapy in patients with hyperuricemia," Modern Rheumatology, vol. 25, no. 1, pp. 123-127, 2015.
[27] Y. Z. Jiang, K. Wang, Y. Li et al., "Enhanced cellular responses and distinct gene profiles in human fetoplacental artery endothelial cells under chronic low oxygen," Biology of Reproduction, vol. 89, no. 6, article 133, 2013.

[28] Y. Z. Jiang, K. Wang, Y. Li et al., "Transcriptional and functional adaptations of human endothelial cells to physiological chronic low oxygen," Biology of Reproduction, vol. 88, no. 5, article 114, 2013.

[29] Y. Z. Jiang, Y. Li, K. Wang et al., "Distinct roles of HIF1A in endothelial adaptations to physiological and ambient oxygen," Molecular and Cellular Endocrinology, vol. 391, no. 1, pp. 60-67, 2014.

[30] J. S. McGonigle, C. M. Giachelli, and M. Scatena, "Osteoprotegerin and RANKL differentially regulate angiogenesis and endothelial cell function," Angiogenesis, vol. 12, no. 1, pp. 35-46, 2009.

[31] S. T. Wang, C. Y. Zhang, C. M. Zhang, C. M. Zhang, and W. Rong, "The plasma osteoprotegerin level and osteoprotegerin expression in renal biopsy tissue are increased in type 2 diabetes with nephropathy," Experimental and Clinical Endocrinology \& Diabetes, vol. 123, no. 2, pp. 106-111, 2015.

[32] P. Secchiero, F. Corallini, A. Pandolfi et al., "An increased osteoprotegerin serum release characterizes the early onset of diabetes mellitus and may contribute to endothelial cell dysfunction," The American Journal of Pathology, vol. 169, no. 6, pp. 2236-2244, 2006.

[33] L. Chen, R. Chen, H. Wang, and F. Liang, "Mechanisms linking inflammation to insulin resistance," International Journal of Endocrinology, vol. 2015, Article ID 508409, 9 pages, 2015.

[34] S. Bernardi, B. Fabris, M. Thomas et al., "Osteoprotegerin increases in metabolic syndrome and promotes adipose tissue proinflammatory changes," Molecular and Cellular Endocrinology, vol. 394, no. 1, pp. 13-20, 2014.

[35] M. Shimamura, H. Nakagami, M. K. Osako et al., "OPG/ RANKL/RANK axis is a critical inflammatory signaling system in ischemic brain in mice," Proceedings of the National Academy of Sciences of the United States of America, vol. 111, no. 22, pp. 8191-8196, 2014.

[36] N. G. Kondegowda, R. Fenutria, I. R. Pollack et al., "Osteoprotegerin and denosumab stimulate human beta cell proliferation through inhibition of the receptor activator of NF- $\kappa \mathrm{B}$ ligand pathway," Cell Metabolism, vol. 22, no. 1 , pp. $77-85,2015$.

[37] A. Weidemann, A. Lovas, A. Rauch et al., "Classical and alternative NF- $\kappa \mathrm{B}$ signaling cooperate in regulating adipocyte differentiation and function," International Journal of Obesity, vol. 40, no. 3, pp. 452-459, 2016.

[38] S. Kiechl, J. Wittmann, A. Giaccari et al., "Blockade of receptor activator of nuclear factor- $\kappa \mathrm{B}$ (RANKL) signaling improves hepatic insulin resistance and prevents development of diabetes mellitus," Nature Medicine, vol. 19, no. 3, pp. 358-363, 2013.

[39] M. B. Loureiro, M. A. Ururahy, F. P. Freire-Neto et al., "Low bone mineral density is associated to poor glycemic control and increased OPG expression in children and adolescents with type 1 diabetes," Diabetes Research and Clinical Practice, vol. 103, no. 3, pp. 452-457, 2014.

[40] K. Suzuki, T. Kurose, M. Takizawa et al., "Osteoclastic function is accelerated in male patients with type 2 diabetes mellitus: the preventive role of osteoclastogenesis inhibitory factor/ osteoprotegerin (OCIF/OPG) on the decrease of bone mineral 
density," Diabetes Research and Clinical Practice, vol. 68, no. 2, pp. 117-125, 2005.

[41] I. Nabipour, B. Larijani, K. Vahdat et al., "Relationships among serum receptor of nuclear factor-kappaB ligand, osteoprotegerin, high-sensitivity C-reactive protein, and bone mineral density in postmenopausal women: osteoimmunity versus osteoinflammatory," Menopause, vol. 16, no. 5, pp. 950-955, 2009.

[42] S. Kudlacek, B. Schneider, W. Woloszczuk, P. Pietschmann, R. Willvonseder, and Austrian Study Group on Normative Values of Bone Metabolism, "Serum levels of osteoprotegerin increase with age in a healthy adult population," Bone, vol. 32, no. 6, pp. 681-686, 2003.

[43] A. E. Altinova, F. Toruner, M. Akturk et al., "Relationship between serum osteoprotegerin, glycemic control, renal function and markers of atherosclerosis in type 2 diabetes," Scandinavian Journal of Clinical and Laboratory Investigation, vol. 71, no. 4, pp. 340-343, 2011.

[44] S. Khosla, H. M. Arrighi, L. J. Melton et al., "Correlates of osteoprotegerin levels in women and men," Osteoporosis International, vol. 13, no. 5, pp. 394-399, 2002.

[45] A. R. Moschen, A. Kaser, S. Stadlmann et al., "The RANKL/ OPG system and bone mineral density in patients with chronic liver disease," Journal of Hepatology, vol. 43, no. 6, pp. 973983, 2005.

[46] M. Shaarawy, S. A. Fathy, N. L. Mehany, and O. W. Hindy, "Circulating levels of osteoprotegerin and receptor activator of NF-kappaB ligand in patients with chronic renal failure," Clinical Chemistry and Laboratory Medicine, vol. 45, no. 11, pp. 1498-1503, 2007.

[47] M. Spartalis and A. Papagianni, "Receptor activator of nuclear factor $\kappa \mathrm{B}$ ligand/osteoprotegerin axis and vascular calcifications in patients with chronic kidney disease," World Journal of Nephrology, vol. 5, no. 1, pp. 1-5, 2016. 


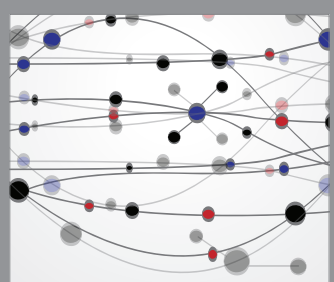

The Scientific World Journal
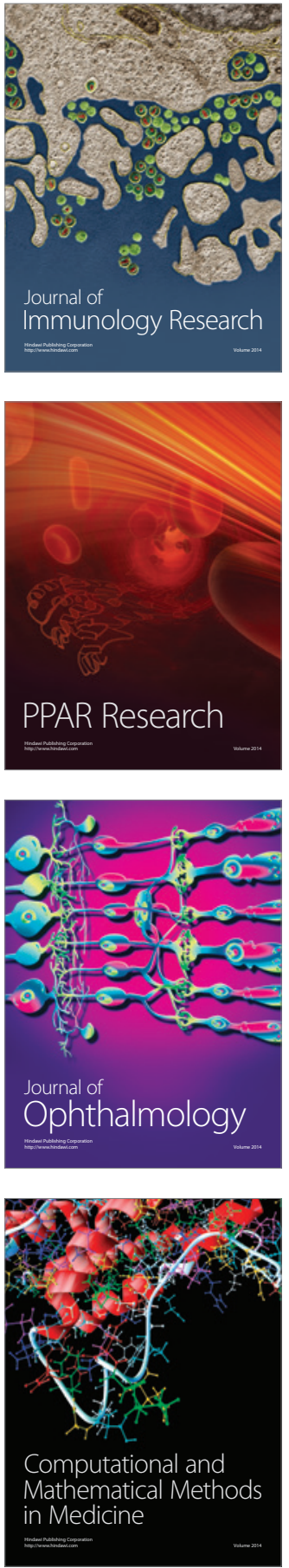

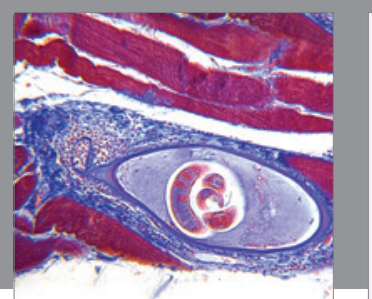

Gastroenterology Research and Practice
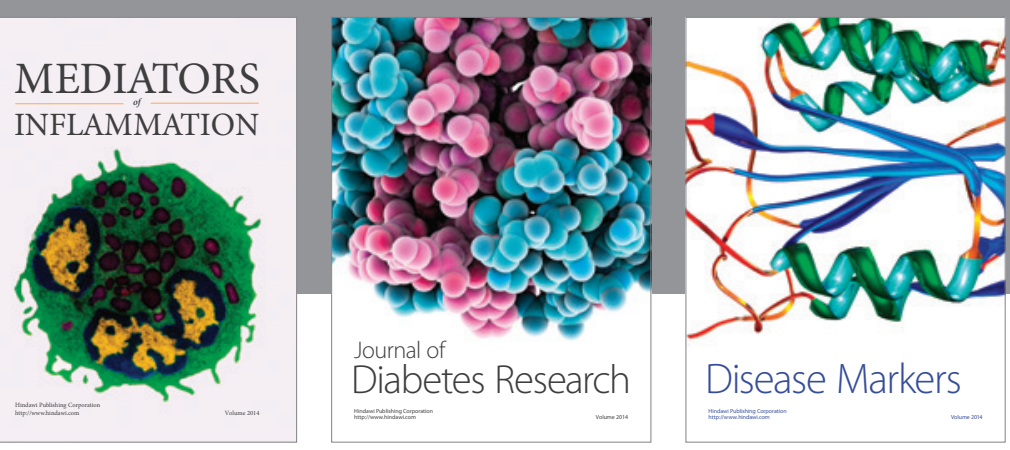

Disease Markers

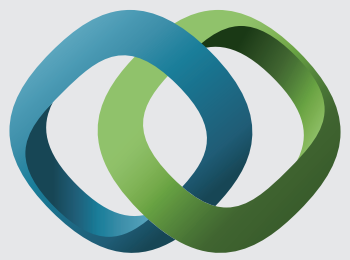

\section{Hindawi}

Submit your manuscripts at

https://www.hindawi.com
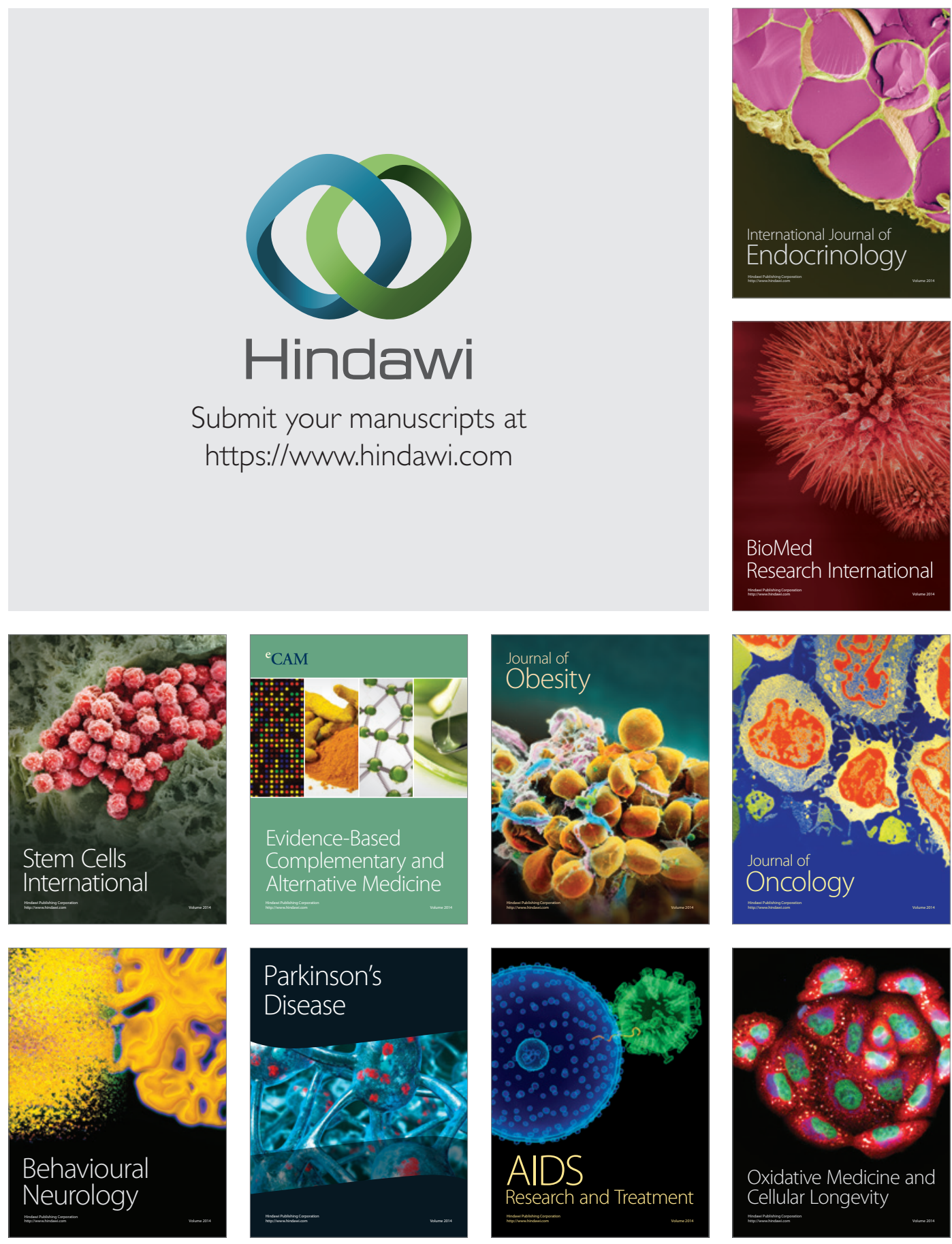